\title{
PHENOTYPIC CHARACTERISTICS OF NATIVE GENOTYPES BELONGING TO KOELERIA GENUS
}

\author{
Rabiya Koyuncu* (D), Mehmet Ali Avci \\ Department of Field Crops, Faculty of Agriculture, University of Selcuk, Turkey \\ rabia@koyuncu.com (*corresponding author),mavci@selcuk.edu.tr
}

\begin{abstract}
Some plant species belonging to the Koeleria genus have many features that make it an ideal grass with low maintenance costs. Their slow growth habit, tolerance to drought and extreme environmental conditions, and their wide natural distribution make them strong candidates for development as grass and forage. In this study, observations and measurements were carried out in 2019-2020 to determine phenotypic characteristics in 53 genotypes selected according to their superior characteristics from Koeleria genotypes collected from the natural flora of Turkey. In Koeleria genotypes; Quality (1-9 scale), seasonal color change (1-9 scale), leaf texture (1-9 scale), density (1-9 scale), plant height (cm), leaf width $(\mathrm{cm})$, leaf length $(\mathrm{cm})$, leaf area $\left(\mathrm{cm}^{2}\right)$, growing type in autumn (1-9 scale), plant diameter (cm), spring regrowth time (1-9 scale), panicle formation tendency (1-9 scale), panicle height (cm ), last internode length (cm), seed yield (g) mean values were $6.90,4.13,4.01,4.73,52.11,0.21,16.15$, 3.42, $3.60,46.33,6.54,5.37,7.69,16.88,4.7$, respectively. Correlation analysis table was created among the phenotypic traits examined and it was found that the traits were significantly effective on each other. Positive correlations between some of these will allow for multi-featured selection in variety improvement. In addition, in the dendrogram created as a result of the cluster analysis, the genotypes are divided into 2 main and 2 subgroups in each main group. This analysis provides ease of selection according to the characteristics focused on these groups for synthetic variety breeding and future breeding studies. As a result of this study, the superior Koeleria genotypes that can be used in breeding studies will be determined.
\end{abstract}

Keywords: Koeleria, quality, selection, genotype

\section{Introduction}

Nowadays, grass plants are perceived as a waste of resources and damage to the environment due to intense water use. There is a need to minimize the cost of growing grass and conserve water. There will be an increasing market for low maintenance grass areas in the near future [1]. Native species are an excellent option for low-maintenance grass areas due to their ability to withstand heat and drought stress with less irrigation needs [2]. Native species should be 
used in breeding programs for their adaptation to a wide variety of soil and climatic conditions [3]. Some species of the Koeleria genus are among the indigenous herbs used as low input grass [4]. These species provide the plant breeders with a wide genetic base from which traits such as grass quality, color, density, mowing quality, growth habit, drought tolerance, disease resistance and seed production can be selected. In addition, it is known that the Koeleria genus needs less input than other cool season grasses [5].

Koeleria Pers. takes its name from Prof. Georg Ludwig Koeler (1765-1807). The Latin name macranthus (called large flower) comes from the connotation of a long, dense panicle. The Koeleria genus belongs to the Poaceae family [6] and includes approximately 60 species in the temperate regions of the world [7]. In Turkey, there are naturally 6 species (Koeleria brevis, Koeleria lobata, Koeleria nitidula, Koeleria eriostachya, Koeleria cristata, Koeleria pyramidata) distribution [8]. The species belonging to the Koeleria genus have a certain importance as forage plants as well as their potential to be used in grass areas. Among the vertebrates, deer, horses and cattle consume the delicious leaves of this plant in June. However, the plant has a limited place in the diet of these animals due to its short length and not being concentrated. In addition, species belonging to this genus can be used in soil improvement, and they provide erosion control by forming structures in the soil thanks to their fibrous root systems [6]. The most distributed species in the Koeleria genus is K. macrantha. K. macrantha is naturally distributed throughout the Northern Hemisphere and varies in morphological features, making accurate identification difficult. Within this species, many subspecies, varieties and subvarieties have been named. Classification schemes can be inconsistent and inaccurate due to polyploidy and wide adaptability [9]. This species has been given many different names, including: K. glauca [9, 10], K. gracilis (L.) Pers., K. cristata (L.) Pers., K. nitida Nutt., K. macrantha (Ledeb.) Schultes [11], K. pyramidata [12], K. pryanidata and K. yukonesis [13]. Known in the Northern Hemisphere, K. macrantha has a wide range of distribution in Europe and Asia. It is found throughout the British Isles, Russia, Siberia, Afghanistan, Iran, Lebanon, Syria, Turkey, India, Kashmir, Nepal, Tibet, China, Japan, Korea, Mongolia and the regions of North Africa and South Africa [10]. K. macrantha is a perennial, cool season (C3) plant that grows to 3-6 dm in height. It is a grass that forms a dense grass, usually without rhizome or stolon. Most of its growth occurs in early spring. In native meadow habitats, K. macrantha is usually the earliest grasses in spring and goes to flowering in June, seed ripening in July, and then a dormant period in the rest of the summer. As water resources become limited, the species avoids dry summer months by completing its breeding cycle before summer drought [5]. $K$. macrantha can be mown as a grass when grown in areas with low annual rainfall and has been found to have some shade tolerance [14]. Koeleria macrantha grows slowly [10-15] and may be useful in reducing mowing frequency. Koeleria macrantha varieties for turf use can lead to a reduction in water, fertilizer and pesticide inputs, resulting in environmental benefits and reduced management costs. Another one of species in the Koeleria genus is K. pyramidata. Phenotypically, $K$. pyramidata is longer than $K$. macrantha, forms denser panicles and has longer and wider leaves. Diseases such as ergot (Claviceps purpurea) can cause morphological changes in the plant making species identification difficult. In addition to morphological features, laboratory techniques can be used to identify and classify species and subspecies or to identify their kinship within the population. K. macrantha (Prairie junegrass) is usually found in sandy soils with low ground water [11]. This species is more tolerant of dry conditions than K. pyramidata [5]. Temperature, precipitation and altitude vary greatly according to the distribution of the species. Koeleria macrantha grows in regions where temperatures could be as low as $-50^{\circ} \mathrm{C}$ (Siberia) in the winter and as high as $39^{\circ} \mathrm{C}$ (Spain) during summer months [10]. Viable seeds were collected from plant material even at temperatures in excess of $40^{\circ} \mathrm{C}$ in South Dakota [5]. The species belonging to the Koeleria genus are cross-pollinating species 
with a low self-pollination rate [10]. Little is known about the seed production characteristics of these species, such as seed head date, harvest date, and seed yield because it has not been extensively studied [5]. Cross-pollinated perennial grasses are typically bred to develop synthetic crosses or improved populations [16].

With this study, it is aimed to use Koeleria genotypes, which have adapted to environmental conditions for hundreds of years, in the scope of synthetic variety breeding, by selecting their superior genotypes in terms of their characteristics of being grass and forage plants. Currently, there is no registered or production permitted Koeleria variety in Turkey [17]. These genotypes we used in our research and the synthetic variety breeding study we have applied will play an important role in the development of Koeleria varieties suitable for the conditions of Turkey.

\section{Material and method}

This research is part of 7 years of synthetic varietal breeding work. The materials used in the study are the genotypes of the Koeleria genus collected in addition to the forage crops collected in 2014-2015 within the scope of the project titled "Turfgrass and Forage Crops to be Used as Natural Flora Found Some Grasses Collection and Use of Breeding Purposes", numbered 1130919, of TÜBİTAK. Although the Koeleria genus was not included in the project, this plant was collected from the nature due to its natural vegetation and the positive characteristics of this plant. These genotypes were collected from nature as both rooted plants and seeds. The collected seeds and rooted plants were replicated under greenhouse conditions and then these plants were replicated by clones. The clones obtained were grown to a suitable size for transplantation into the field. In July-August 2015, the clones belonging to the Koeleria genus were planted in the experimental field at $0.5 \mathrm{~m} \times 0.5 \mathrm{~m}$ intervals. The soil structure of the trial area is clay- loam (EC: 0.88 ds.m-2, pH: 8.10, organic matter 2.4\%, CaCO3: 35.5\%). The average temperature in 2019, in which the research was carried out, was 14.2 0C, in 202014.7 0C, and the average temperature for many years (1929-2020) was 11.7 0C. It is seen that these values are higher than the long-term average. When the total precipitation data are examined, the annual total precipitation was $353.4 \mathrm{~mm}$ in 2019, $303.6 \mathrm{~mm}$ in 2020, and $329.2 \mathrm{~mm}$ for many years. The annual average relative humidity values were determined as $55.85 \%$ in 2019 and $52.92 \%$ in 2020. For the plants, irrigation was carried out during the first planting times and when the summer is very hot and the rainfall is low. Weed control was done by hand and hoe as necessary during each growing season. Any fertilization has not been done. The mowing process was applied regularly after harvesting the seeds before entering the winter. From the Koeleria genotypes in the experimental area, 53 genotypes were selected according to their superior characteristics. While performing this selection; Especially in genotypes intended for use in green areas, those with high quality (such as disease-resistant, uniform appearance), those that maintain their greenness for a long time, those with high density and thin leaf-width genotypes were selected. The selected genotypes belong to different species of the Koeleria genus. The taxonomy of Koeleria species is quite complex and identification and classification of the species requires serious expertise. Because Koeleria species in the same genus are very similar to each other, they can easily crossbreed between them and form hybrid species, and because of natural variation, there are serious problems in the diagnosis of these species. In addition, polyploidy is very common in Koeleria species, and even the same species has forms with different chromosome numbers. Therefore, the identification of these plants will be made in future studies. Observations and measurements were taken in the 53 selected Koeleria genotypes in 2019-2020. In the observations and measurements made: Tamkoç et al. [18-19] made use of the final reports of TUBITAK projects. 


\subsection{Observations and measurements in research}

2.1.1. Quality (1-9 scale): Quality was visually evaluated as a combination of color, density, uniformity, texture, disease or reaction to environmental stresses. $1=$ Weakest $/$ Worst, $6=$ Acceptable, 9 = Superior / İdeal.

2.1.2. Seasonal Color Change (1-9 scale): The colors of the plants are determined separately according to the seasons. Since different colors from blue to dark green were observed in the Koeleria genotypes we examined, different scale values were used to determine the color. In determining this value, $1=$ Blue $3=$ Bluish Green $5=$ Light Green $7=$ Green $9=$ Dark Green .

2.1.3. Leaf Texture (1-9 scale): Leaf texture is the visual measure of leaf width. The evaluation was made by considering the developed leaf of a stem that could form a panicle. It was evaluated as $1=$ Narrow/Delicate, $5=$ Medium, 9=Wide/Coarse.

2.1.4. Density (1-9 scale): Density is the visual estimation of the amount of shoots per unit area. Shoot density varies according to different times of the year. Density observations were made in spring, summer and autumn and climatic differences were observed.

1 = Very Rare, 3 = Rare, 5 = Medium, 7 = Frequent, 9 = Very Often.

2.1.5. Plant Height (cm): The height of the plant taken on at least 3 stalks that have completed its development was determined by measuring the distance between the soil surface and the extreme point of the stems in $\mathrm{cm}$.

2.1.6. Leaf Width (cm): The width of the leaf that has completed its development in the stems whose plant height was measured was measured and recorded in $\mathrm{cm}$.

2.1.7. Leaf Length (cm): The leaf length of the leaves, whose leaf width was measured, was measured with the help of a ruler and recorded in $\mathrm{cm}$.

2.1.8. Leaf Area $\left(\mathbf{c m}^{2}\right)$ : It was calculated in $\mathrm{cm}^{2}$ as a result of the product of leaf width and height.

2.1.9. Growing Type in Autumn (1-9): Growing Type in Autumn was observed in the first year. The observations were made visually considering the angle of the plant habitus with the soil surface. Scale values: $1=$ Perpendicular, $3=$ Semi-Perpendicular, $5=$ Medium, $7=$ Subhorizontal., 9 = Horizontal.

2.1.10. Plant Diameter $(\mathbf{c m})$ : The area covered by each plant is calculated by measuring perpendicular to each other and taking its average.

2.1.11. Spring Regrowth Time (1-9 scale): $1=$ Never Lasted or Died, $3=$ Not Lasted (Late), 5 = Lasted (Medium), 7 = Lasted Well (Early), 9 = Very Early (Always Developing).

2.1.12. Panicle Formation Tendency (1-9 scale): When at least three panicles were seen in the plants, it was recorded for each genotype. $1=$ None or Weak, $3=$ Weak, $5=$ Medium, $7=$ Strong, 9 = Strongest.

2.1.13. Panicle Height (cm): In the stalks which plant height measured has been determined by measuring the distance in $\mathrm{cm}$ from the node where the flag leaf comes out to the point where the first spike comes out. 
2.1.14. Seed Yield (g): When the plants reached seed harvest maturity, each plant was harvested separately and after drying in the open air, threshing was carried out. Seeds were cleaned of stalks and glumes. Then the seeds were weighed in a weighing with 0.01 precision.

The relationships between these features were determined by correlation analysis. JMP 13 statistical analysis was used to evaluate the data.

\section{Results and discussion}

The observations and measurements made in Koeleria genotypes are given in Table 1. As can be seen from the examination of Table 1, the average values are as follows. Quality 6.90; seasonal color change 4.13; leaf texture 4.01; density 4.73; plant height $52.11 \mathrm{~cm}$; leaf width $0.21 \mathrm{~cm}$; leaf height $16.15 \mathrm{~cm}$; leaf area is $3.42 \mathrm{~cm}^{2}$; growing type in autumn 3.60; plant diameter $46.33 \mathrm{~cm}$; spring regrowth time 6.54; panicle formation tendency 5.37; panicle height $7.69 \mathrm{~cm}$; last internode length $16.88 \mathrm{~cm}$ and seed yield was observed or measured as $4.7 \mathrm{~g}$. The evaluation of the combination of features such as looking beautiful, being in harmony in terms of color, structure and form and their reactions to disease or environmental stresses in grass plants is evaluated with the quality of the grass. Measuring grass quality is a difficult and subjective task that relies on the grower's visual ratings over time to evaluate various traits [20]. The quality of the Koeleria plant genotypes was determined to be in general good condition with the smallest 6, the largest 9 (ideal-superior) and the average value of 6.90. Genetic color grades range from light to dark and dark green is generally preferred [5]. Although there are plants with dark green color in the genotypes we observed, the average color we obtained is bluish green. This color is capable of creating a beautiful image in landscape areas. In previous years, observations and measurements were made on the plants we selected from the Koeleria genotypes. According to these observation and measurement results, in Koeleria genotypes in 2016-2017: Grass quality 7.1; seasonal color change 4.86; leaf texture 3.22; density 4.7; plant height $45.2 \mathrm{~cm}$; leaf width $0.29 \mathrm{~cm}$; leaf height is $7.72 \mathrm{~cm}$; leaf area $2.31 \mathrm{~cm}^{2}$; growing type in autumn 4.48; plant diameter $14.7 \mathrm{~cm}$; spring regrowth time 6.2; panicle formation tendency 4.62; panicle size $7.38 \mathrm{~cm}$; last internode length $22.5 \mathrm{~cm}$ and seed yield was observed or measured as $1.39 \mathrm{~g}$ [21]. In 2017-2018, species were determined as Koeleria cristata and Koeleria pyramidata and observations and measurements were made accordingly. Average values in Koeleria cristata genotypes are as follows. Grass quality 6.92; seasonal color change 5.56; density 4.76; leaf texture 3.56; plant height $46.76 \mathrm{~cm}$; leaf width $0.27 \mathrm{~cm}$; leaf height 10.4 $\mathrm{cm}$; growing type in autumn 4.12; plant diameter $17.4 \mathrm{~cm}$; panicle size $8.72 \mathrm{~cm}$; last internode length $23.3 \mathrm{~cm}$. In the Koeleria pyramidata genotypes; Grass quality 6.2; seasonal color change 5.66; density 5.4; leaf texture 4.6; plant height $44.46 \mathrm{~cm}$; leaf width $0.17 \mathrm{~cm}$; leaf height 7.13 $\mathrm{cm}$; growing type in autumn 3.4; plant diameter $32.13 \mathrm{~cm}$; panicle height $8.46 \mathrm{~cm}$; last internode length was found to be $12.6 \mathrm{~cm}$ [22]. As a result of this research, it is seen that plant height, leaf height and seed yield are higher than the results of previous years and other observation and measurement results are similar in all three studies. This can be explained as the genotypes maintain their characteristics. The small differences seen are thought to be caused by the differences in climate. 
Table 1. Average, highest, lowest, standard deviation (Sd) and coefficient of variation (CV) values of the properties examined in Koeleria genotypes

\begin{tabular}{|c|c|c|c|c|c|c|}
\hline Properties & $\begin{array}{l}\text { Number of } \\
\text { materials }\end{array}$ & Average & Lowest & Highest & Sd & CV (\%) \\
\hline Quality (1-9) & 53 & 6.90 & 6 & 9 & 1.39 & 20.13 \\
\hline $\begin{array}{l}\text { Seasonal Color } \\
\text { Change (1-9) }\end{array}$ & 53 & 4.13 & 1 & 9 & 2.75 & 66.79 \\
\hline $\begin{array}{l}\text { Leaf Texture (1- } \\
\text { 9) }\end{array}$ & 53 & 4.01 & 1 & 9 & 2.46 & 61.43 \\
\hline Density (1-9) & 53 & 4.73 & 3 & 9 & 1.46 & 31.03 \\
\hline Plant Height (cm) & 53 & 52.11 & 15 & 96 & 21.59 & 41.43 \\
\hline Leaf Width (cm) & 53 & 0.21 & 0.1 & 0.36 & 0.07 & 32.76 \\
\hline $\begin{array}{l}\text { Leaf Length } \\
\text { (cm) }\end{array}$ & 53 & 16.15 & 5 & 50 & 9.49 & 58.80 \\
\hline $\begin{array}{l}\text { Leaf Area } \\
\left(\mathrm{cm}^{2}\right)\end{array}$ & 53 & 3.42 & 0.65 & 10.5 & 2.26 & 66.01 \\
\hline $\begin{array}{l}\text { Growing Type } \\
\text { in Autumn (1- } \\
\text { 9) }\end{array}$ & 53 & 3.60 & 1 & 7 & 2.13 & 59.19 \\
\hline $\begin{array}{l}\text { Plant Diameter } \\
(\mathrm{cm})\end{array}$ & 53 & 46.33 & 15 & 70 & 13.69 & 29.55 \\
\hline $\begin{array}{l}\text { Spring } \\
\text { Regrowth Time } \\
(1-9)\end{array}$ & 53 & 6.54 & 5 & 9 & 1.44 & 22.12 \\
\hline $\begin{array}{l}\text { Panicle } \\
\text { Formation } \\
\text { Tendency (1-9) }\end{array}$ & 53 & 5.37 & 3 & 9 & 2.25 & 41.93 \\
\hline $\begin{array}{l}\text { Panicle } \\
\text { Height (cm) }\end{array}$ & 53 & 7.69 & 5 & 14 & 2.32 & 30.20 \\
\hline $\begin{array}{l}\text { Last Internode } \\
\text { Length }(\mathrm{cm})\end{array}$ & 53 & 16.88 & 10 & 30 & 4.57 & 27.10 \\
\hline Seed Yield (g) & 53 & 4.7 & 0.3 & 15 & 3.40 & 72.45 \\
\hline
\end{tabular}

Avcioğlu et al [6], plant height 30-70 cm, leaf height 2-20 cm in Koeleria species, Dore and McNeill [23], leaf width 0.1-0.3 cm, Shaw [13] found that the last node length was 8.9-38.1 cm and the panicle height was $4-5 \mathrm{~cm}$. The color of the plant was determined by Avcioğlu et al [6] as silver-green. Dixon [10] stated that the number of spikelets per inflorescence ranged from 20-200 and the inflorescences ranged from green to purple. The average values we have obtained and the studies carried out by these researchers are similar. However, considering the smallest and highest values we have obtained, slight differences are observed. The highest values we obtained in terms of plant height $(96 \mathrm{~cm})$, leaf length $(50 \mathrm{~cm})$, panicle height $(14 \mathrm{~cm})$ are higher than the values obtained from these studies. While the leaf width is the same with the results of this research, the last node length is smaller $(30 \mathrm{~cm})$. The reason for these differences may be due to the polyploidy-genetic structure seen in plants or the ecological environment differences. Correlation analysis was performed to determine the relationships between the traits examined in Koeleria genotypes. The binary relationships between the plant traits examined are given in Table 2. 
Table 2. Correlation coefficients (r) between traits examined in Koeleria genotypes

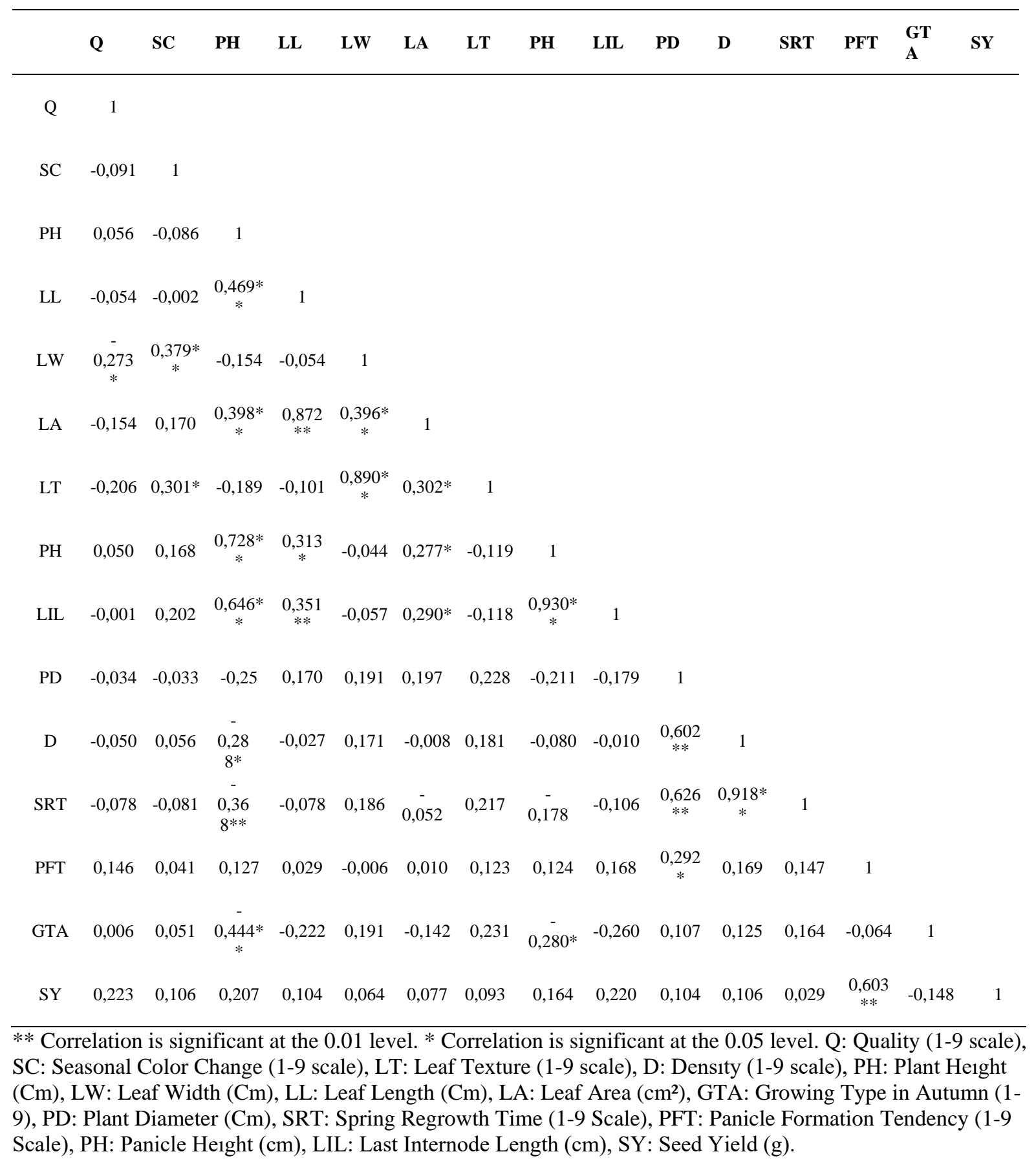

As can be seen when Table 2 is examined, there is a negative relationship at the level of $5 \%$ between quality and leaf width. As the leaf width decreases, the quality increases. The thinness of the leaf is a desirable feature for grass areas. There is a positive relationship between seasonal color change and leaf width (1\%) and leaf texture (5\%). It is revealed that those with thick and coarse leaves are dark green in color, while those with thin and delicate texture are blue. While there is a positive relationship of $1 \%$ between plant height and leaf length, leaf area, panicle height, last internode length, there is a negative relationship with the spring regrowth time and the growing type in autumn (1\%). In other words, it means that those with taller plants are latish species and grow more steep. In addition, it is observed that as the plant height increases, the density decreases ( $5 \%$ negative relationship). There is a positive relationship between leaf 
length and leaf area and last internode length (1\%) and panicle height (5\%). There is a 1\% positive relationship between leaf width and leaf area and leaf texture. Those with the highest leaf width are considered as coarse. There is a 5\% positive relationship between leaf area and leaf texture, panicle height, and last internode length. While there is a $1 \%$ positive relationship between panicle height and last internode length, there is a $5 \%$ negative correlation between panicle height and growing type in autumn. It has been found that the habitat of plants that are long in panicle height is steeper. There is a $1 \%$ positive relationship between plant diameter and density and spring regrowth time, and a $5 \%$ positive relationship with the panicle formation tendency. There is a $1 \%$ positive and significant relationship between density and spring regrowth time. It has been demonstrated that genotypes with larger diameters form denser, earlier and more panicles. Since those with large plant diameters cover the area more quickly, it is more suitable for use in grass areas. Finally, 1\% positive and significant relationship was found between panicle formation tendency and seed yield. It is seen that the seed yields of genotypes with strong panicle formation tendency are also high. Johnson [24] stated that seed yield is generally inversely related to grass quality and these characteristics should be balanced. According to our correlation analysis results, there is no significant positive or negative relationship between these features. Seed production characteristics of the Koeleria genus will be important in the selection of high yielding genotypes with quality turf performance. Since it has not been extensively researched as a seed plant, little is known about the flowering characteristics of this species (anesis date, pollination shedding times, yield, need for vernalization, etc.). The growth of the Koeleria genus usually begins in April and, depending on the ecotype, inflorescences appear throughout June. Koeleria genus is a cross-pollinating genus with a low incidence of selfing [10]. Dore and McNeill [23] suggest that species of this genus do not produce seeds when grown in isolation and seems self-incompatible. At maturity, $65 \%$ of seed disperses up to one meter from the maternal plant, with the rest remaining on the panicles [10]. Hacker and Cuany [25] correlated the inflorescence number and inflorescence length more positively with seed yield and stated that it could be used as an indirect selection criterion. The seeds of the grasses used for the green field are less produced and expensive. It is not possible to produce varieties that have low seed production or cannot be produced commercially. Regardless of the purpose of the breeding study, genotypes with high seed yield per plant stand out directly in selection, together with high other characteristics. Cluster analyzes were made to classify the Koeleria genotypes used in the study and are given in Figure 1.

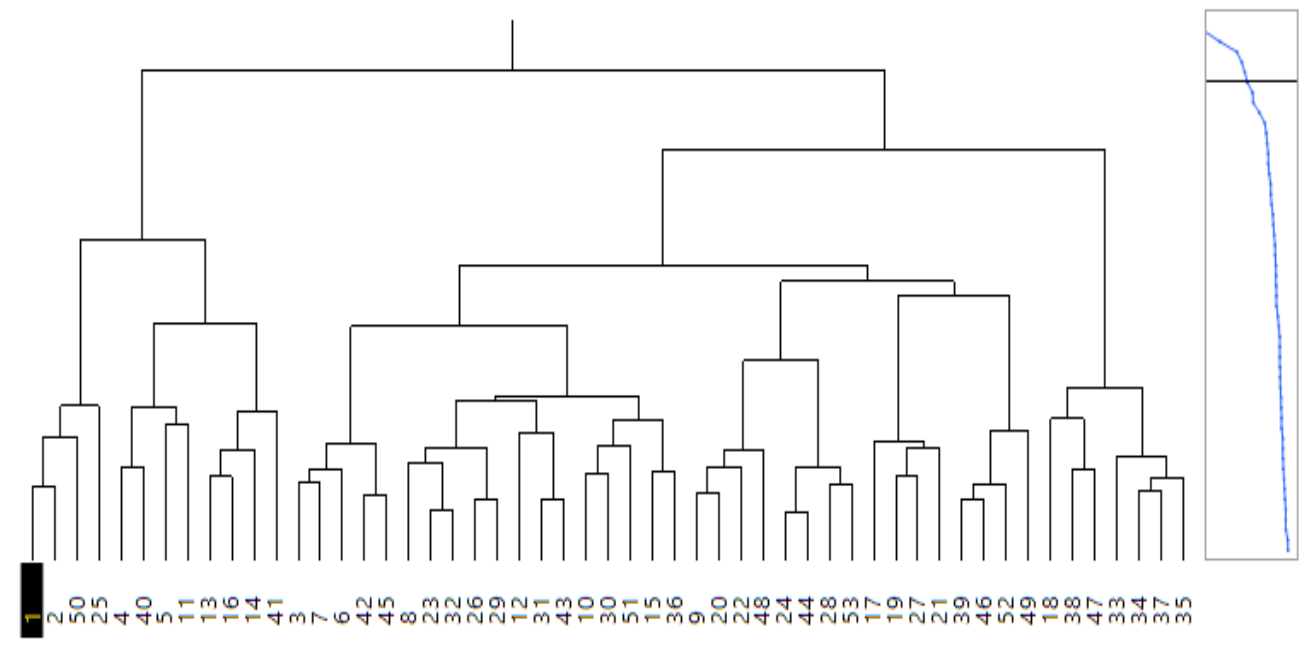

Figure 1. Cluster analysis in terms of traits examined in Koeleria genotypes 
As a result of the cluster analysis, it was determined that Koeleria genotypes were divided into 2 main groups (Figure 1) and that the distance varied in the range of 1.14-11.60 values, that the nearest genotypes were genotypes 24 to 44, and that the farthest distance was genotypes 1 to 3 . This analysis creates groups for plants that have common characteristics and allows us to choose as many plants with common characteristics to work with. According to the results of this analysis, plants with thin leaf width, dark green color and delicate texture were collected in a group. Priority will be given to plants in this group in the breeding work to be carried out for grass areas. Selections will be made from groups that grow more coarsely with the purpose of forage crop breeding, grow perpendicular for mowing, and grow horizontally for grazing. In this way, it is thought that time and labor will be saved. In addition, the ones with high seed yield are important in both selections. This is because the continuity of genotypes will be ensured and seeds will be produced commercially.

\section{Conclusions}

As a result Koeleria genotypes with superior characteristics that can be used in future breeding studies were determined. It has been observed that it is necessary to continue the breeding of genotypes, which have superior characteristics from the Koeleria plants studied, and to develop varieties suitable for the conditions of our country and region. By increasing such studies, the preservation of gene resources will be ensured by using them as well as storing them. In addition, with this study, infrastructural data were created for those who want to work on Koeleria.

\section{Acknowledgments}

Rabiya Koyuncu is sponsored via a fellowship from the YÖK 100/2000 doctorate program.

\section{References}

[1] Zurek G., "Strzeplice [Koeleria sp.]- malo znane gatunki do zadarniania terenow suchych”, Czesc II. Ocena przydatnosci trawnikowej. Lakarstwo w Polsce (Grassland Science in Poland) 3(2000) : 185-192.

[2] Johnson, P. G., "An overview of North American native grasses adapted to meet the demand for low-maintenance turf”, Diversity 16 (2000) : 40-41.

[3] Willms, W. D., Ellert, B. H., Janzen, H. H., Douwes, H., "Evaluation of native and introduced grasses for reclamation and production”, Rangeland Ecol. \& Manage 58 (2005) : 177-183.

[4] Watkins, E., Clark, M. D., “Genetic improvement of prairie junegrass”, USGA Turfgrass and Environ. Res. Online 8 (2009) : 1-8.

[5] Clark, M. D., "Evaluation of the genetic potential of prairie junegrass (Koeleria macrantha) for use as a low-input turfgrass”, A Thesis Submitted to The Faculty of The Graduate School of The University of Minnesota (2010).

[6] Avcioğlu, R., Hatipoğlu, R., Karadağ, Y., "Forage crops from grass and other families”. Textbook 3 (2009) : 657-665. 
[7] Edgar, E., Gibb, E. S., “Koeleria Pers. (Gramineae: Aveneae) in New Zealand”, N.Z. J. Bot. 31 (1999) : 51-61.

[8] Tübives., "Turkish Plants Data Service”, Retrieved in February, 9, 2021 from http://www.tubives.com (2021).

[9] Dixon, J.M., “On the status of the genus Koeleria Pers. (Poacea) in Britain”, Watsonia 23 (2001) : 377-390.

[10] Dixon, J. M., “Koeleria macrantha (Ledeb.) Schultes (K. alpigena Domin, K. cristata (L.) Pers. pro parte, K. gracilis Pers., K. albescens auct. non DC.)”, J. Ecol. 88 (2000) : 709-726.

[11] Quintanar, A., Castroviejo, S., “Taxonomic revision of Koeleria (Poaceae) in the Western Mediterranean Basin and Macaronesia”, Systematic Botany 38(4) (2013) : 1029-1061.

[12] Kucera, C.L., "The grasses of Missouri”, University of Missouri Press, Columbia, MO (1998).

[13] Shaw, R. B., “Grasses of Colorado”, University Press of Colorado, Boulder, CO (2008).

[14] Brede, D., “Turfgrass maintenance reduction handbook: Sports, lawns, and golf”, Sleeping Bear Press, Chelsea, MI (2000).

[15] Soovali, P., Bender, A., "The occurrence of powdery mildew on crested hairgrass in different growing conditions”, Agron. Res. 4 (2006) : 385-388.

[16] De Araujo, M. R. A., Coulman, B. E., “Genetic variation, heritability and progeny testing in meadow bromegrass”, Plant Breeding 121 (2002) : 417-424.

[17] Anonymous., “T.R. Ministry of Agriculture and Forestry Seed Registration and Certification Central Directorate. National Variety List (Field Crops)”, Retrieved in January, 10, 2021 from https://www.tarimorman.gov.tr/BUGEM/TTSM/Sayfalar/Detay .aspx?SayfaId=85 (2021).

[18] Tamkoç, A., Avcı, M. A., Özköse, A., "Collection and breeding of perennial grass (Lolium perenne L.) genotypes found in natural flora”, TUBITAK Project Final Result Report, No: 1060159 (2009).

[19] Tamkoç, A., Avcı, M. A., Özköse, A., "Collected from the natural flora and some plant characteristics determined perennial grass (Lolium perenne L.) Development of Genotypes By Synthetic Cultivar Breeding Method”, TUBITAK Project Final Result Report, No:110O312 (2013).

[20] Morris, K. N., Shearman, R. C., “NTEP turfgrass evaluation guidelines [Online]”, Available at http://www.ntep.org/pdf/ratings.pdf (verified 01/19/2010). Nat.Turfgrass Eval. Prog., Beltsville, MD (2008).

[21] Levent, Z., Avc1, M. A., "Determination of morphological diversity in Koeleria cristata (L.) Pers. Genotypes collected from the nature”, BŞEÜ Journal of Science 7 (2020) : 78 86.

[22] Avc1, M. A., Koyuncu, R., "Determınatıon of some agricultural properties of Koeleria PERS. Genotypes collected from nature”, Current Developments in Agriculture and Livestock (2020) : 122-133.

[23] Dore, W. G., McNeill, J., “Grasses of Ontario”, Canadian Government Pub Centre, Ottawa (1980).

[24] Johnson, P. G., "Mixtures of buffalograss and fine fescue or streambank wheatgrass as a low-maintenance turf”, Hort Science 38 (2003) : 1214-1217. 
[25] Hacker, J. B., Cuany, R. L., "Genetic variation in seed production and its components in four cultivars of the pasture grass Setaria sphacelata”, Euphytica 93 (1997) : 271-282. 